\title{
Acid-triggered core cross-linked nanomicelles for targeted drug delivery and magnetic resonance imaging in liver cancer cells
}

This article was published in the following Dove Press journal:

International Journal of Nanomedicine

9 August 2013

Number of times this article has been viewed

Xian $\mathrm{Li}^{1, *}$

$\mathrm{HaO} \mathrm{Li}^{2,4, *}$

Wei $\mathrm{Yi}^{3}$

Jianyu Chen'

Biling Liang'

'Radiology Department, The Sun Yat-Sen Memorial Hospital, Sun Yat-Sen University, Guangzhou, People's Republic of China; ${ }^{2}$ Center of Biomedical Engineering, School of Chemistry and Chemical Engineering, Sun Yat-Sen University, Guangzhou, People's Republic of China; ${ }^{3}$ Radiotherapy Department, The First Affiliated Hospital, Guangzhou Medical University, Guangzhou, People's Republic of China; ${ }^{4}$ School of Engineering, Sun Yat-Sen University, Guangzhou, People's Republic of China

*These authors contributed equally to this work
Purpose: To research the acid-triggered core cross-linked folate-poly(ethylene glycol)$b$-poly[N-( $\mathrm{N}^{\prime}, \mathrm{N}^{\prime}$-diisopropylaminoethyl) glutamine] (folated-PEG-P[GA-DIP]) amphiphilic block copolymer for targeted drug delivery and magnetic resonance imaging (MRI) in liver cancer cells.

Methods: As an appropriate receptor of protons, the N,N-diisopropyl tertiary amine group (DIP) was chosen to conjugate with the side carboxyl groups of poly(ethylene glycol)- $b$-poly (L-glutamic acid) to obtain PEG-P(GA-DIP) amphiphilic block copolymers. By ultrasonic emulsification, PEG-P(GA-DIP) could be self-assembled to form nanosized micelles loading doxorubicin (DOX) and superparamagnetic iron oxide nanoparticles (SPIONs) in aqueous solution. When PEG-P(GA-DIP) nanomicelles were combined with folic acid, the targeted effect of folated-PEG-P(GA-DIP) nanomicelles was evident in the fluorescence and MRI results.

Results: To further increase the loading efficiency and the cell-uptake of encapsulated drugs (DOX and SPIONs), DIP ( $\mathrm{pK}_{\mathrm{a}} \approx 6.3$ ) groups were linked with $\sim 50 \%$ of the side carboxyl groups of poly(L-glutamic acid) (PGA), to generate the core cross-linking under neutral or weakly acidic conditions. Under the acidic condition (eg, endosome/lysosome), the carboxyl groups were neutralized to facilitate disassembly of the P(GA-DIP) blocks' cross-linking, for duly accelerating the encapsulated drug release. Combined with the tumor-targeting effect of folic acid, specific drug delivery to the liver cancer cells and MRI diagnosis of these cells were greatly enhanced.

Conclusion: Acid-triggered and folate-decorated nanomicelles encapsulating SPIONs and DOX, facilitate the targeted MRI diagnosis and therapeutic effects in tumors.

Keywords: acid-triggered, DOX, nanomicelle carrier, folate-targeted effect, SPIONs

\section{Introduction}

Effective targeted nanoparticle encapsulating contrast agents could have a large impact on the future of early MRI tumor diagnosis. As a sensitive and negative contrast agent, superparamagnetic iron oxide nanoparticles (SPIONs) could be encapsulated into some nanomicelles. A previous study indicated that folate-functionalized poly(ethylene glycol)-b-poly( $\varepsilon$-caprolactone) (PEG-PCL) micelles were used for targeted delivery of magnetic resonance imaging (MRI) contrast agents and antitumor drugs. ${ }^{1}$ These nanocarriers have attracted great interest, due to their multifunctional characteristics, including the ability to target special cell surface receptors of cancer cells ${ }^{2,3}$ For example, a previous study reported that the tumor-targeted multifunctional nanomicelles loading SPIONs and doxorubicin (DOX) could be used for MRI diagnosis and targeted cancer therapy. ${ }^{4}$
Correspondence: Biling Liang; Jianyu Chen

The Sun Yat-Sen Memorial Hospital,

Sun Yat-Sen University,

Yanjiang Street, Guangzhou,

510120, People's Republic of China

Tel +86208306 2066

Fax +862081332833

Email blliang61@yahoo.cn; cjygz08@।63.com 
Polymeric nanocarriers, particularly nanosized micelles capable of passive or active targeted effect, have long been considered an appropriate and reliable delivery system of SPIONs. ${ }^{5-7}$ However, similar to the drug's encapsulation, the high contrast parameters of SPIONs depend on the stability and loading efficiency of the micelles, which may require the specific and smart modification of the nanocarriers. During the storage and transportation of drug carriers, widely practiced core cross-linking effectively prevents the encapsulated agents from being released and the shell-core structure from decomposing prematurely. Hereinto, covalent cross-linking is an approach that is frequently used to stabilize drug encapsulations. ${ }^{8-10}$ Environmentally, responsive technologies (eg, those based on $\mathrm{pH}$ sensitivity, thermal sensitivity, and redox sensitivity), combined with covalent cross-linking, have exhibited outstanding performance in the controlled release of encapsulated drugs. ${ }^{11-15}$ In addition, ionic cross-linking, namely the electrostatic interaction between the positive and negative charges of the hydrophobic polymer blocks, is also a good choice in the micellar core. ${ }^{16}$

On the other hand, weakly acidic interstitial fluid (pH 6.75-7.23) in solid tumors and acidic endosomes/ lysosomes ( $\mathrm{pH} 4.0-5.5$ ) in cells possess the characteristic acidic environment. ${ }^{17}$ Using these factors, it is possible to construct acid-responsive nanocarriers, whose drug release is triggered in a site-specific manner for malignant tumors. In this process, some acid-sensitive chemical groups which become deprotonated in a neutral environment and protonated in an acidic environment are introduced into the hydrophobic segment of the amphiphilic block copolymers, to build up the drug-loaded nanomicelles. Based on such a structural design, the hydrophobic core of the nanocarriers undergoes a hydrophobic to hydrophilic transition once trapped in the acidic environment (endosome/lysosome), which leads to the swelling or even collapse of the nanoassemblies, and thus triggering the fast release of the encapsulated drugs into the hydrophobic core. In previous reports, modified acid-sensitive poly(acrylic acid) (PAA) and poly(amino acid) commonly were used to construct the site-specific drug nanocarriers. ${ }^{18,19}$ Although PAA can easily be functionalized to respond to external stimuli (such as light, heat, and acid), in vivo application of the drug carrier is greatly limited due to its non-biodegradability. Compared to PAA, poly(amino acid)s such as poly(Lglutamic acid) (PGA), ${ }^{20,21}$ poly(L-aspartic acid), ${ }^{17,22}$ and poly(L-lysine $)^{17,22,23}$ have better in vivo biocompatibility and biodegradability, and bear reactive side carboxyl or primary amine groups that can easily be modified to confer stimuli-responsive capabilities. Moreover, as an available acid-responsive polypeptide, PGA could undergo a sharp-phase transition by helix-coil conformational change to significantly benefit the accelerative release of the entrapped drug, once the $\mathrm{pH}$ value is close to or below its $\mathrm{pK}_{\mathrm{a}}(\leq 4.25) \cdot{ }^{24,25}$

In the present study, PGA was chosen as the basic component for the construction of the hydrophobic block of the amphiphilic copolymers in acid-sensitive nanomicelles. To enable acid-sensitivity according to the inter- or intracellular environment of live cancer cells, N,N-diisopropyl tertiary amine group (DIP, $\left.\mathrm{pK}_{\mathrm{a}} \approx 6.3\right)^{26}$ was grafted to PGA through amidation. In the neutral aqueous solution, synthesized folate-terminal poly(ethylene glycol)- $b$-poly $\left[\mathrm{N}-\left(\mathrm{N}^{\prime}, \mathrm{N}^{\prime}-\right.\right.$ diisopropylaminoethyl) glutamine] (folate-PEG-P[GA-DIP]) was used to produce self-assembled nanomicelles for suitable drug encapsulation and delivery. In a weakly acidic substance (the tumor-intercellular substance), DIP $\left(\mathrm{pK}_{\mathrm{a}} \approx 6.3\right.$ ) could accept one proton to convert hydrophobic P(GA-DIP) blocks into hydrophilic electropositive ones. To obtain the ionic cross-linking between the electropositive P(GA-DIP) and the remaining electronegative carboxyl groups of PGA ( $\mathrm{pK}_{\mathrm{a}} \approx 4.25$ ), DIP was grafted to $\sim 50 \%$ of the PGA's carboxyl groups for stability of the nanomicelles. If DIP segments were grafted to $100 \%$ carboxyl groups of PGA (without the remaining carboxyl groups), the strong repulsion among the protonated P(GA-DIP) blocks would destabilize and disassemble the nanomicelles, initiating drug release at too high a rate. In an acidic substance (eg, endosome/lysosome), these carboxyl groups of PGA $\left(\mathrm{pK}_{\mathrm{a}} \approx 4.25\right)$ could be protonated to become electroneutral and hydrophobic components, according to the carboxyl's properties. In this case, an attraction could not exist between the electropositive P(GA-DIP) segments and the remaining electroneutral carboxyl groups of PGA, thus, terminating the ionic cross-linking and triggering fast drug release.

If the nanomicelles are connected with the tumortargeted folate-ligands, the encapsulated DOX and SPIONs would effectively be entrapped in the cancer cells for tumor-specific chemotherapy and MRI. The folate receptor (FR) is a valuable therapeutic target that is highly expressed in a variety of cancers, including liver cancer. ${ }^{27}$ To further observe the target effect in the present article, the folate-PEG-P(GA-DIP) nanocarriers encapsulating DOX and SPIONs were evaluated in the human liver cell line Bel-7402. Poly(ethylene glycol)-b-poly(D,L-lactic acid) (PEG-PDLLA) and PEG-PCL nanomicelles were used as contrasts. 


\section{Materials and methods}

\section{Synthesis and characterization of folate-PEG-P(GA-DIP)}

According to the synthetic route of folate-PEG-P(GADIP) (shown in Figure 1), $\alpha$-allyl- $\omega$-hydroxy poly(ethylene glycol) (allyl-PEG-OH) $\left(\mathrm{M}_{\mathrm{n}}\right.$ [number average molecular weight]: $1000 \mathrm{~g} / \mathrm{mol}$ ) was synthesized by an anionic ringopening polymerization of ethylene oxide initiated by potassium naphthalide, as described in earlier reports, ${ }^{28,29}$ which was followed by the conversion into $\alpha$-allyl- $\omega$-amino poly(ethylene glycol) (allyl-PEG-NH ${ }_{2}$ ). ${ }^{30,31}$ The synthesis and purification of $\gamma$-benzyl-L-glutamate N-carboxyanhydride (BLG-NCA) followed the established methodology, and originated from L-glutamic acid (Sinopharm Chemical Reagent Co, Ltd, Shanghai, People's Republic of China). ${ }^{32-34}$ Allyl-poly(ethylene glycol)- $b$-poly( $\gamma$-benzyl L-glutamate) (allyl-PEG-PBLG) was prepared using a standard NCA method. ${ }^{35,36}$ The removal of the benzyl group in PBLG block was achieved using an acid deprotection method. ${ }^{37,38}$ After N,N-carbonyl diimidazole (CDI; Sigma-Aldrich, St Louis, MO, USA), activated by N,N-diisopropylamino ethylamine (DIPAEA; Sigma-Aldrich), was linked to the side carboxyl group of the synthesized allyl-polyethylene glycol-b-poly(Lglutamate) (allyl-PEG-PGA), the terminal allyl group was converted into an amino group on the base of a radical addition reaction of 2-aminoethanethiol hydrochloride, allowing it

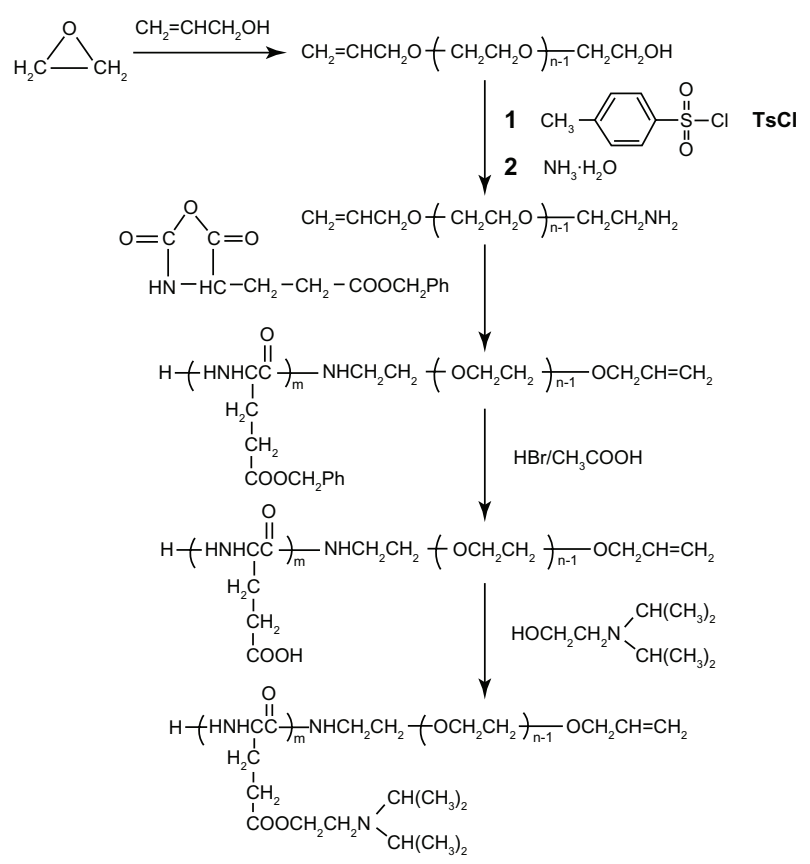

Figure I Synthetic route of allyl-PEG-P(GA-DIP).

Note: I represents $\mathrm{TsCl}$ and 2 represents $\mathrm{NH}_{3} \cdot \mathrm{H}_{2} \mathrm{O}$.

Abbreviation: allyl-PEG-P(GA-DIP), allyl-poly(ethylene glycol)-b-poly[N-( $\mathrm{N}^{\prime}, \mathrm{N}^{\prime}$ diisopropylaminoethyl) glutamine]. to link with folic acid (BR; Sinopharm Chemical Reagent Co, Ltd), preactivated by N-hydroxysuccinimide (NHS; SigmaAldrich) and dicyclohexylcarbodiimide (Sigma-Aldrich). ${ }^{28,29}$ Then the main products were characterized by proton nuclear magnetic resonance $\left({ }^{1} \mathrm{H}-\mathrm{NMR}\right)$ spectroscopy (Mercury-Plus 300; Varian Medical Systems Inc, Palo Alto, CA, USA) as shown in Figure 2. For experimental preparation, DIPAEA was redistilled under high vacuum conditions. All analytic grade reagents were redistilled and dried before synthesis. All dialyzers (Shanghai Green Bird Technology Development Co, Ltd, Shanghai, People's Republic of China) were saved in a $1 \mathrm{mM}$ aqueous ethylene diamine tetraacetic acid (EDTA) solution.

For the contrast groups in the drug release test, the PEGPDLLA and PEG-PCL diblock copolymers were synthesized by the ring opening polymerizations of the lactone monomer in the presence of a stannous octoate catalyst, and initiated by allyl-PEG-OH $\left(\mathrm{M}_{\mathrm{n}}: 6000 \mathrm{~g} / \mathrm{mol}\right)$ or methoxy- $\omega$-hydroxy polyethylene glycol $\left(\mathrm{M}_{\mathrm{n}}: 2000 \mathrm{~g} / \mathrm{mol}\right)$, respectively. ${ }^{39}$ The molecular weights $\left(\mathrm{M}_{\mathrm{w}}\right)$ of poly(L-lactide) and the PCL block as determined from ${ }^{1} \mathrm{H}-\mathrm{NMR}$ were $2000 \mathrm{~g} / \mathrm{mol}$ and $20,000 \mathrm{~g} /$ mol, respectively.

\section{Preparation and characteristics of the DOX and SPION-loaded PEG-P(GA-DIP) nanomicelles} Preparation of the DOX and SPION-loaded PEG-P(GA-DIP) nanomicelles

SPION nanoparticles $\left(6 \mathrm{~nm}, \mathrm{Fe}_{3} \mathrm{O}_{4}\right.$ particles $)$ were synthesized according to the previously reported methods. ${ }^{40}$ Dimethyl sulfoxide (DMSO)/tetrahydrofuran solution ( $2 \mathrm{~mL}$, volume ratio $=1: 1)$ containing $10 \mathrm{mg}$ copolymer, $2 \mathrm{mg}$ hydrophobic DOX (in acid-base titration) (Zhejiang Hisun Pharmaceuticals Co, Ltd, Shanghai, People's Republic of China) and $2 \mathrm{mg}$ hydrophobic SPION (6 $\mathrm{nm} \mathrm{Fe}_{3} \mathrm{O}_{4}$ particles) was added droplet by droplet into $7 \mathrm{~mL}$ ultrapure water under ultrasonic action. Then this mixture was dialyzed against water ( $\mathrm{M}_{\mathrm{w}}$ cut-off: $\left.1000 \mathrm{Da}\right)$ for 2 days. The formation of micelles is shown in Figure 3.

\section{Determination of the DOX and SPION-loaded PEG-P(GA-DIP) nanomicelles}

The configuration of micelles was revealed using a thermal field emission environmental scanning electron microscope (SEM; Quanta 400; FEI Company, Hillsboro, OR, USA). The particle sizes of the obtained micelles were measured by a zeta potential and particle-size analyzer (Zeta Plus/90Plus; Brookhaven Instruments Corporation, Holtsville, NY, USA) 


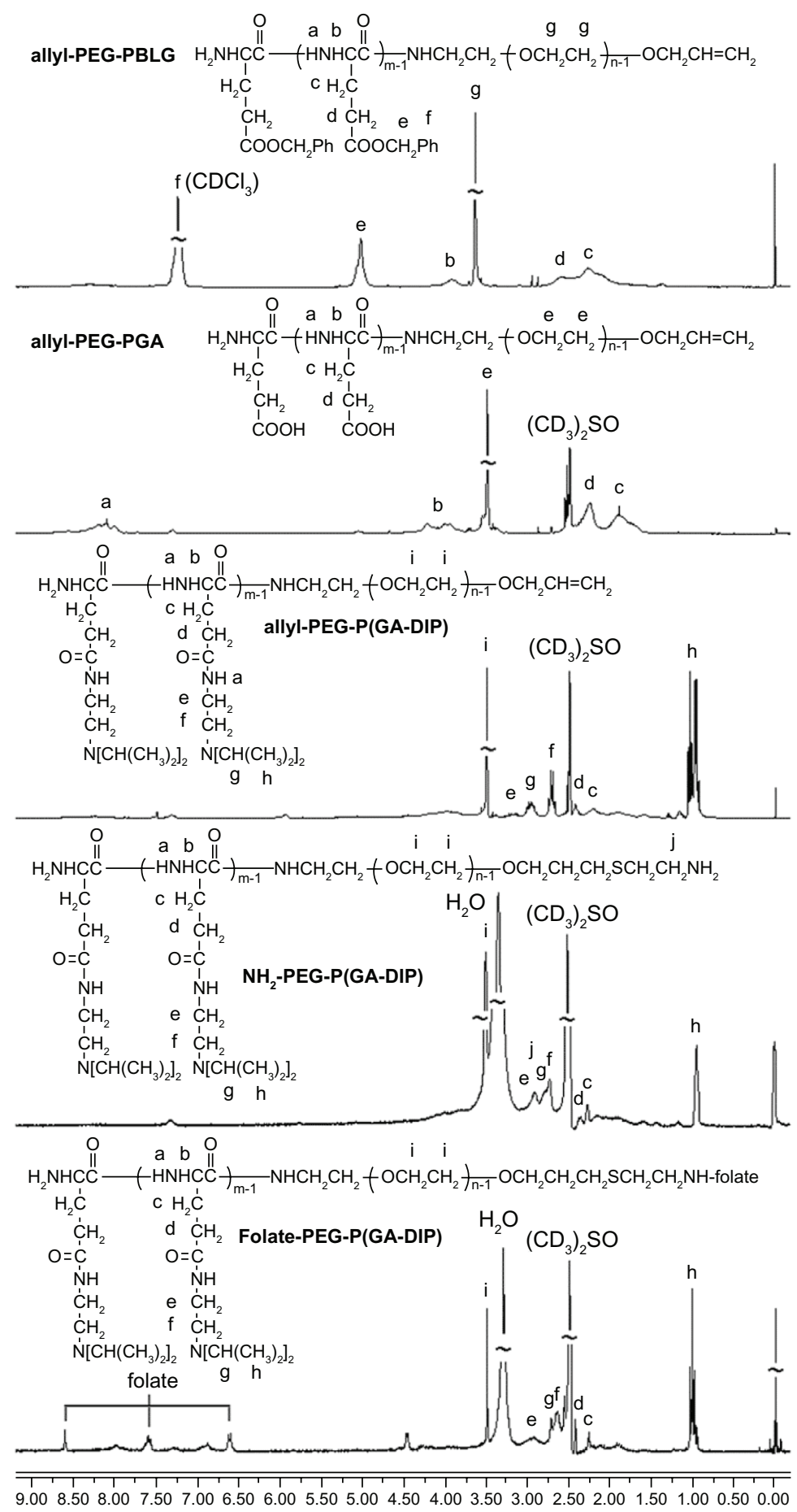

Figure 2 'H-NMR spectrums of allyl-PEG-P(GA-DIP)'s conversion from allyl-PEG-PBLG to folate-PEG-P(GA-DIP).

Abbreviations: 'H-NMR, proton nuclear magnetic resonance; PBLG, b-poly( $\gamma$-benzyl L-glutamate); PEG-P(GA-DIP), poly(ethylene glycol)-b-poly[N-(N',N'-diisopropylaminoethyl) glutamine]; PGA, poly(L-glutamic acid).

in ultrapure water. The SPION and DOX concentration in the nanomicelles was detected by the following methods. Lyophilized dialyzate $(3 \mathrm{~mL})$ was dissolved in $10 \mathrm{~mL}$ DMSO/ chloroform solution (volume ratio $=1: 1$ ). The maximal DOX absorbance was determined over the range $482-502 \mathrm{~nm}$, using an ultraviolet-visible (UV-Vis) near-infrared spectrophotometer
(UV-3150; Shimadzu, Kyoto, Japan) to quantify the loading of DOX in the micelles. Similarly, $1 \mathrm{~mL}$ of lyophilized dialyzate was fully dissolved in $5 \mathrm{~mL} 10 \% \mathrm{HCl}$ aqueous hydrochloric acid solution to determine the loading of SPION, using an atomic absorption spectrophotometer (Model: Z-2000; Hitachi Ltd, Tokyo, Japan). 


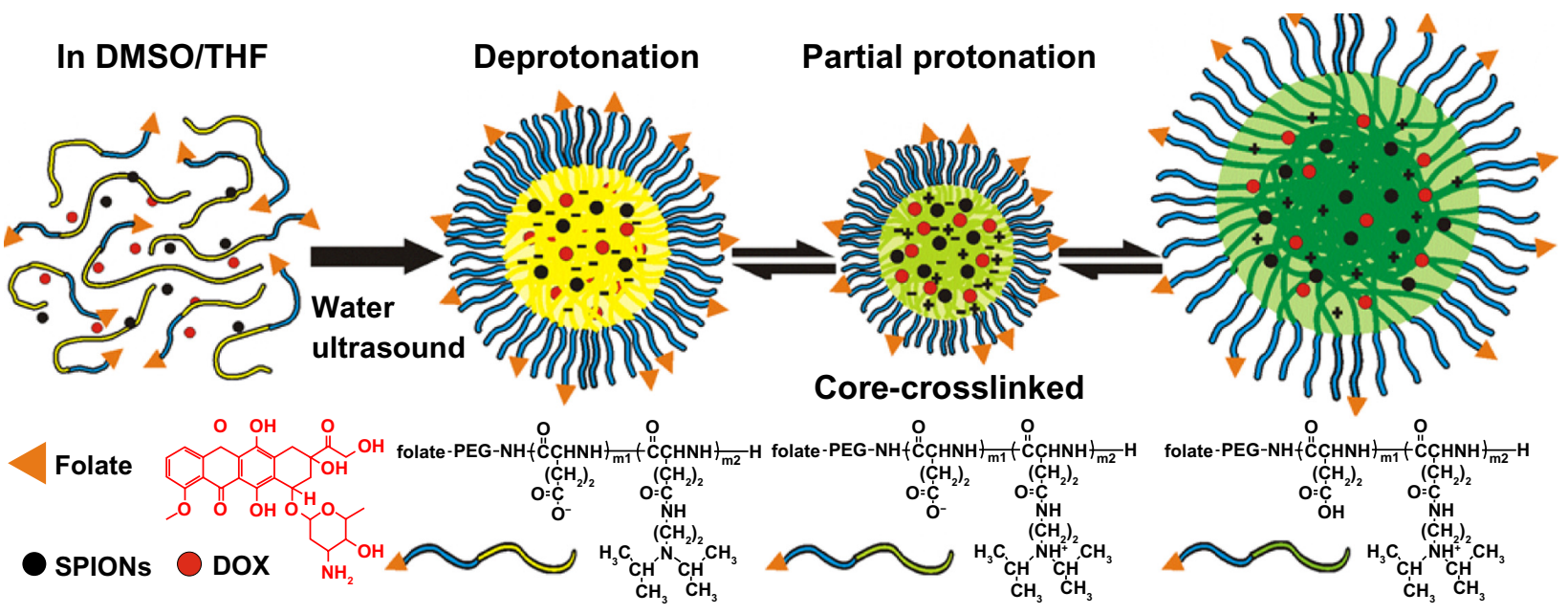

Figure 3 Acid-triggered self-assembly of folate-PEG-P(GA-DIP) nanomicelles loading DOX and SPIONs.

Abbreviations: DOX, doxorubicin; DMSO, dimethyl sulfoxide; folate-PEG-P(GA-DIP), folate-poly(ethylene glycol)-b-poly[N-(N',N'-diisopropylaminoethyl) glutamine]; SPIONs, superparamagnetic iron oxide nanoparticles; THF, tetrahydrofuran.

\section{Particle sizes of DOX and SPION-loaded micelles at different $\mathrm{pH}$ values}

Several samples, which included a $5 \mathrm{~mL}$ solution of the allylPEG-P(GA-DIP) micelles loading DOX and SPION (about $0.56 \mathrm{mg} / \mathrm{mL}$ ) and $3 \mathrm{~mL}$ ultrapure water, were adjusted to various stable $\mathrm{pH}$ values (range 3.0-7.0). The particle sizes under different $\mathrm{pH}$ environments were measured using a zeta potential and particle size analyzer (ZetaPlus/90Plus).

\section{Drug release from various DOX and SPION-loaded micelles}

Various freeze-dried nanomicelles including PEG-PCL, PEGPDLLA, and PEG-P(GA-DIP) (20 mg each) were resuspended in phosphate-buffered saline (PBS). Each nanomicelle solution was divided equally into two parts and transferred into different dialysis bags ( $\mathrm{M}_{\mathrm{w}}$ cut-off: 14,000 Da). Three dialysis bags (including three nanomicelles in each) were placed in $25 \mathrm{~mL}$ PBS solution with a $\mathrm{pH}$ of 7.0. The other three dialysis bags were placed in $25 \mathrm{~mL}$ PBS solution with a $\mathrm{pH}$ of 5.0.

The release study was performed at $37^{\circ} \mathrm{C}$ in two incubator shakers (ZHWY-200B; Shanghai ZHICHENG Analytical Instrument Manufacturing Co, Ltd, Shanghai, People's Republic of China). At predetermined time intervals, $5 \mathrm{~mL}$ PBS solution outside of the dialysis bag was replaced. The released DOX in the replaced PBS solution could be detected using UV-Vis analysis $(480 \mathrm{~nm})$. Fresh PBS solutions of $\mathrm{pH}$ 5.0 and 7.0 were added into two shakers, to retain a constant $\mathrm{pH}$ environment in the shakers. Then the percentages of the released DOX were calculated cumulatively. Every cumulative release curve for a specific $\mathrm{pH}$ value was expressed as an average of two series of tests per sample.

\section{Cell biology experiment}

\section{Fluorescence microscopy}

The receptors of folic acid were abundant on the surface of human hepatic carcinoma cells (Bel-7402). The cells were purchased from the Experimental Animal Center of Sun Yat-Sen University (Guangzhou, People's Republic of China). A folate-free Roswell Park Memorial Institute (RPMI) 1640 medium (Life Technologies, Carlsbad, CA, USA) was used, which was supplemented with $10 \%$ heatinactivated fetal bovine serum.

To indicate the successful encapsulation of DOX into folate-PEG-P(GA-DIP) nanomicelles, Bel-7402 cells $\left(1 \times 10^{5}\right)$ were mixed with the PBS and folate-PEG-P(GA-DIP) (DOX concentration of 0.19 and $0.76 \mu \mathrm{g} / \mathrm{mL}$, respectively). The nanomicelles were not added into the cells of the PBS contrast group.

In the second test, Bel-7402 cells $\left(1 \times 10^{5}\right)$ were mixed with the folate-targeted folate-PEG-P(GA-DIP) nanomicelles in the targeted group $(0.76 \mu \mathrm{g} / \mathrm{mL}$ DOX concentration). In the non-targeted group, the cells were mixed with the nontargeted PEG-P(GA-DIP) nanomicelles $(0.76 \mu \mathrm{g} / \mathrm{mL}$ DOX concentration). In the competitive inhibition group, cells were incubated with folate-PEG-P(GA-DIP) nanomicelles $(0.76 \mu \mathrm{g} / \mathrm{mL}$ DOX concentration) and $1 \mathrm{mM}$ free folic acid.

After 2 hours of incubation, the cells were washed three times with $0.5 \mathrm{~mL}$ PBS to remove the non-ingested and free nanomicelles. Fluorescence microscopy (A1, Axio Observer; Carl Zeiss Microscopy Gmbh, Jena, Germany) was used to observe the intracellular DOX fluorescence at $490 \mathrm{~nm}$. Then the relative fluorescence uptake was obtained by a 
flow cytometer (FACSCalibur; Becton Dickinson, San Jose, CA, USA). The free DOX solution was incubated with cells in the contrast group. Note that the free DOX solution and DOX-loaded nanomicelles had the same DOX concentration. Finally, the relative fluorescence uptake was calculated by comparing the cell DOX fluorescence of the test groups to that of the contrast group.

\section{In vitro MRI scan}

After 24 hours of incubation in a humidified incubator $(5 \%$ $\left.\mathrm{CO}_{2}\right)$ at $37^{\circ} \mathrm{C}$, Bel-7402 cells $\left(5 \times 10^{6}\right)$ were mixed with folate-PEG-P(GA-DIP) nanomicelles at different iron (Fe) concentrations $(0.358,0.179,0.0895$, and $0.04475 \mu \mathrm{g} / \mathrm{mL})$. After 2 hours of incubation, the cells were washed three times with $1 \mathrm{~mL}$ PBS, and then digested using pancreatic enzyme. The cell solutions were centrifuged, and the supernatant liquid was removed. Then the cell sediment was mixed with $150 \mu \mathrm{L}$ gelatin (4\%) to suspend the cell sediment again. The cell suspension was scanned by a 1.5T MRI scanner (Philips Intera 1.5T; Philips, Amsterdam, Netherlands). PBS without cell sediment was used as the blank contrast. In the gelatin control group, cells were not incubated with nanomicelles and the cell sediment was mixed with gelatin to maintain the stability of the cell suspension.

In the second test, Bel-7402 cells $\left(5 \times 10^{6}\right)$ were mixed with the folate-targeted folate-PEG-P(GA-DIP) nanomicelles and the non-targeted PEG-P(GA-DIP) nanomicelles at $0.179 \mu \mathrm{g} / \mathrm{mL}$ Fe concentration. In the competitive inhibition group, cells were incubated with folate-PEG-P(GADIP) nanomicelles using a combination of $0.179 \mu \mathrm{g} / \mathrm{mL} \mathrm{Fe}$ concentration and $1 \mathrm{mM}$ free folic acid together. Folic acid competed with the folate-PEG-P(GA-DIP) nanomicelles for folate-receptors. In the contrast group, the nanomicelles were not added into the cells and the cell sediment was mixed with gelatin. After 2 hours of incubation, the cell suspensions were taken and scanned.

A circular surface coil with an inner diameter of $11 \mathrm{~cm}$ was used to take the T2-weighted images and T2-mapping images. The T2-weighted images were acquired using the following parameters: repetition time/echo time (TR/TE) of $2600 \mathrm{~ms} / 100 \mathrm{~ms}$; field of view (FOV) of $150 \mathrm{~mm}$; matrix of $512 \times 512$; and slice thickness of $0.6 \mathrm{~mm}$. The T2-mapping images were acquired using the following parameters: SE 8-echo sequence; TR/TE of $1300 \mathrm{~ms} /(10-90) \mathrm{ms}$; FOV of $150 \mathrm{~mm}$; matrix of $512 \times 512$; and slice thickness of $0.6 \mathrm{~mm}$. The T2-mapping images were color-coded: blue represented a low value and red represented a high value. Then the T2 values of different groups were calculated.

\section{Results and discussion Synthesis of folate-PEG-P(GA-DIP)}

Due to their steric stabilization, biocompatibility, and excellent solubility in aqueous media, the PEG-based macroinitiators have been widely used for preparing diblock and triblock copolymers. As shown in Figure 1, the obtained allyl-PEG$\mathrm{NH}_{2}$ was employed as an initiator to synthesize allyl-PEGPBLG by the ring-opening polymerization of BLG-NCA. After deprotection of the benzyl group, the activated DIP was connected to the side carboxyl group of the PGA block in the allyl-PEG-PGA copolymer.

Figure 2 shows the ${ }^{1} \mathrm{H}-\mathrm{NMR}$ spectra of the intermediate product (PEG-PBLG, PEG-PGA) and the final PEG-P(GADIP) nanomicelles. The $-\mathrm{CH}_{2}-$ peaks in the repeated PEG blocks of the intermediate and final products were close to $3.5 \mathrm{ppm}$ in all the ${ }^{1} \mathrm{H}-\mathrm{NMR}$ spectra. For instance, the $-\mathrm{CH}_{2}-$ peak in PEG-PBLG was at 3.48 ppm ("g" peak), the peak in PEG-PGA was at 3.48 ppm ("e" peak), and the peak in PEG-P(GA-DIP) was at 3.54 ppm ("i”" peak). In the spectra of PEG-PBLG, the " $\mathrm{f}$ " peak at $7.19 \mathrm{ppm}$ represented $\mathrm{C}_{6} \mathrm{H}_{5}$ - in the PBLG block, indicating successful synthesis of PEGPBLG. In the spectra of PEG-PGA, the peak at $7.19 \mathrm{ppm}$ was not clearly observed, indicating the removal of the benzyl group in PEG-PBLG and successful synthesis of PEG-PGA. The " $h$ " peak at $\sim 1.0$ ppm reflected the $\mathrm{CH}_{3}-$ signal in DIP and indicated successful synthesis of PEG-P(GA-DIP). Furthermore, the PEG-P(GA-DIP) structure was calculated by comparing the integral ratios of different characteristic peaks (listed in Table 1). These peaks included $-\mathrm{CH}_{2}-$ in PEG ("i" peak at $\sim 3.5 \mathrm{ppm}$ ), the first $-\mathrm{CH}_{2}-$ of side chain in PGA ("d" peak at 2.26 ppm), and $\mathrm{CH}_{3}$ - in DIP ("h" peak at $\sim 1.0 \mathrm{ppm}$ ). More importantly, the grafting percentage of the DIP groups was $48.15 \%$, very close to $50 \%$, similar to the previously determined value. This indicated that $\sim 50 \%$ of the carboxyl groups of PGA were grafted with DIP, with 50\% of the PGA's carboxyl groups remaining.

The three peaks (at $6.6 \mathrm{ppm}, 7.6 \mathrm{ppm}$, and $8.6 \mathrm{ppm}$ ) shown in Figure 2 (the ${ }^{1} \mathrm{H}-\mathrm{NMR}$ spectra of folate-PEG-P[GA-DIP]) indicated the presence of the folate-ligand in the folate-PEG$\mathrm{P}(\mathrm{GA}-\mathrm{DIP})$ and successful linkage between the folate and the terminal amino of the PEG block after 5 days of dialysis.

\section{Characteristics of the DOX and SPION-loaded nanomicelles Detection of the DOX and SPION-loaded PEG-P(GA-DIP) nanomicelles}

SEM images indicated the existence of spherical particles ( $\sim 60 \mathrm{~nm}$ in diameter), which suggested the formation of 
Table I Chemical structure and carrier performances of allyl-PEG-P(GA-DIP), folate-PEG-P(GA-DIP), and contrast copolymers

\begin{tabular}{|c|c|c|c|c|}
\hline Sample & Allyl-PEG-P(GA-DIP) & Folate-PEG-P(GA-DIP) & PEG-PDLLA & PEG-PCL \\
\hline Molecular weight of PEG block (g/mol) & 1000 & 1000 & 6000 & 6000 \\
\hline Amount of repeating units of PBLG & 2 & 2 & & \\
\hline Amount of repeating units of PGA & 12 & 12 & & \\
\hline Amount of repeating units of $P(G A-D I P)$ & 13 & 13 & & \\
\hline Molecular weight of hydrophobic block $(\mathrm{g} / \mathrm{mol})$ & 6700 & 6700 & 2000 & 20,000 \\
\hline Total molecular weight $(\mathrm{g} / \mathrm{mol})$ & 7700 & 7700 & 8000 & 22,000 \\
\hline Grafting percent of DIP (\%) & 48.2 & 48.2 & & \\
\hline Loading efficiency of DOX (\%)* & $16.0 \pm 3.3$ & $1.1 \pm 0.2$ & $6.3 \pm 0.8$ & $8.1 \pm 1.9$ \\
\hline Encapsulation percent of DOX (\%)* & $39.7 \pm 6.9$ & $3.2 \pm 2.1$ & $20.2 \pm 1.6$ & $42.7 \pm 9.8$ \\
\hline Loading efficiency of SPIONs (\%)* & $2.2 \pm 0.6$ & $2.2 \pm 1.2$ & $5.6 \pm 1.1$ & $9.3 \pm 1.0$ \\
\hline Encapsulation percent of SPIONs (\%)* & $7.8 \pm 0.2$ & $5.5 \pm 0.4$ & $6.6 \pm 2.9$ & $14.1 \pm 1.5$ \\
\hline Particle size $(\mathrm{nm})^{*}$ & $58.9 \pm 0.4$ & $65.8 \pm 6.9$ & $53.5 \pm 3.0$ & $226.2 \pm 3.2$ \\
\hline
\end{tabular}

Notes: All data about chemical structure were calculated by relative 'H-NMR spectrum. *Expressed as the averaging of at least three results.

Abbreviations: DIP, N,N-diisopropyl tertiary amine group; DOX, doxorubicin; 'H-NMR, proton nuclear magnetic resonance; PBLG, b-poly( $\gamma$-benzyl L-glutamate); PEG-P(GA-DIP), poly(ethylene glycol)-b-poly[N-(N',N'-diisopropylaminoethyl) glutamine]; PGA, poly(L-glutamic acid); SPIONs, superparamagnetic iron oxide nanoparticles; PEG-PDLLA, poly(ethylene glycol)-b-poly(D,L-lactic acid); PEG-PCL, poly(ethylene glycol)-b-poly(e-caprolactone).

allyl-PEG-P(GA-DIP) micelles (Figure 4). Successful detection of DOX and SPIONs (Table 1) allowed for the encapsulation of DOX and SPIONs in the nanomicelles. The encapsulation of DOX and SPIONs was also verified by the tests of MRI and fluorescence.

In general, the nanomicelles with a longer hydrophobic block had the larger self-assembled micelles and higher drug loading. In the present research, PEG-PCL and PEGPDLLA were also prepared for the contrast groups. Hence, the PEG-PCL micelle loading DOX and SPIONs had the largest particle size $(226.2 \mathrm{~nm})$ and highest encapsulation percentage of DOX and SPIONs (42.7\% and $14.1 \%$, respectively) among all nanomicelles in Table 1. Interestingly, the

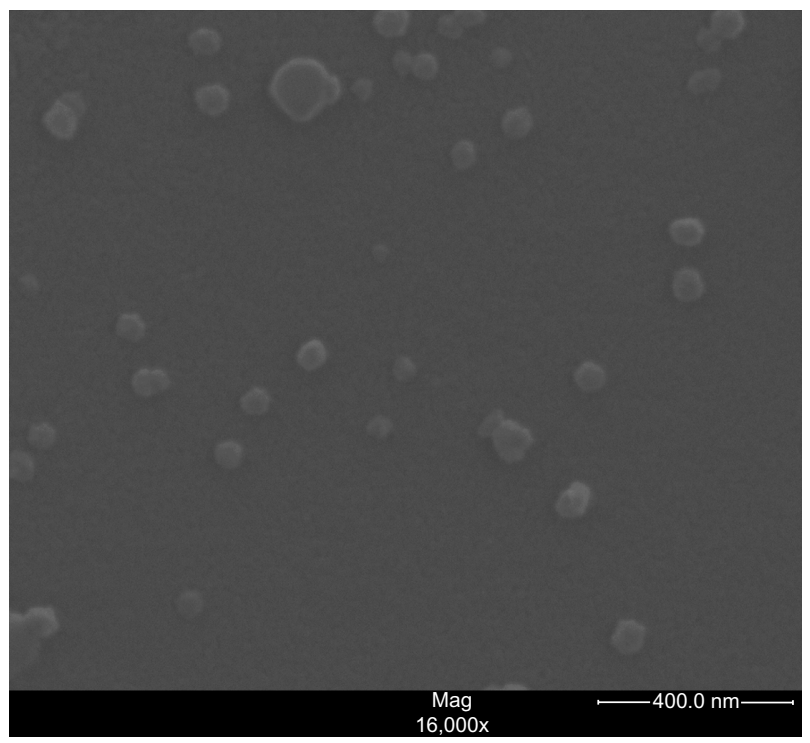

Figure 4 SEM images of DOX and SPION-loaded allyI-PEG-P(GA-DIP) micelles. Abbreviations: allyl-PEG-P(GA-DIP), allyl-poly(ethylene glycol)-b-poly[N-(N',N'diisopropylaminoethyl) glutamine]; DOX, doxorubicin; SPIONs, superparamagnetic iron oxide nanoparticles; Mag, magnification.
allyl-PEG-P(GA-DIP) micelle exhibited a similar encapsulation percentage of DOX, close to that of PEG-PCL (39.7\% versus $42.7 \%)$. And the DOX loading efficiency of the allyl-PEG-P(GA-DIP) micelle was higher than that of PEG-PCL (16\% versus $8.1 \%)$. In a neutral aqueous solution, one primary amino group of partial DOX $\left(\mathrm{pK}_{\mathrm{a}}=8.6\right)$ was protonated and bound with the remaining carboxyl groups of PGA $\left(\mathrm{pK}_{\mathrm{a}} \approx 4.25\right)$. An attraction existed between the electropositive DOX and the remaining electronegative carboxyl groups of PGA. Hence, we chose only $50 \%$ of the PGA's carboxyl groups to connect with the DIP, to achieve a high encapsulation percentage and loading efficiency of DOX. If the grafting between DIP and the carboxyl groups of PGA reached $100 \%$, then the remaining carboxyl groups disappeared and the DOX loading decreased. Of course, the above situation did not exist in the encapsulation percentage of acid-covered SPIONs. The encapsulation percentage of allyl-PEG-P(GA-DIP) (7.8\%) was lower than that of PEGPCL (14.1\%).

In addition, the DOX and SPION encapsulation percentages of folate-PEG-P(GA-DIP) (3.2\% and 5.5\%, respectively) were lower than that of allyl-PEG-P(GA-DIP). During the formation of folate-PEG-P(GA-DIP) micelles, the primary amino groups of the outer folic acid molecules partially inhibited DOX from embedding itself into the P(GA-DIP) core, which resulted in a low DOX encapsulation percentage and loading efficiency, different from the allyl-PEG-P(GADIP) micelles.

\section{Particle sizes of the drug-loaded PEG-P(GA-DIP)} micelles at different $\mathrm{pH}$ values

Figure 5 shows the particle sizes of the drug-loaded allyl-PEG-P(GA-DIP) micelles in various $\mathrm{pH}$ environments. 


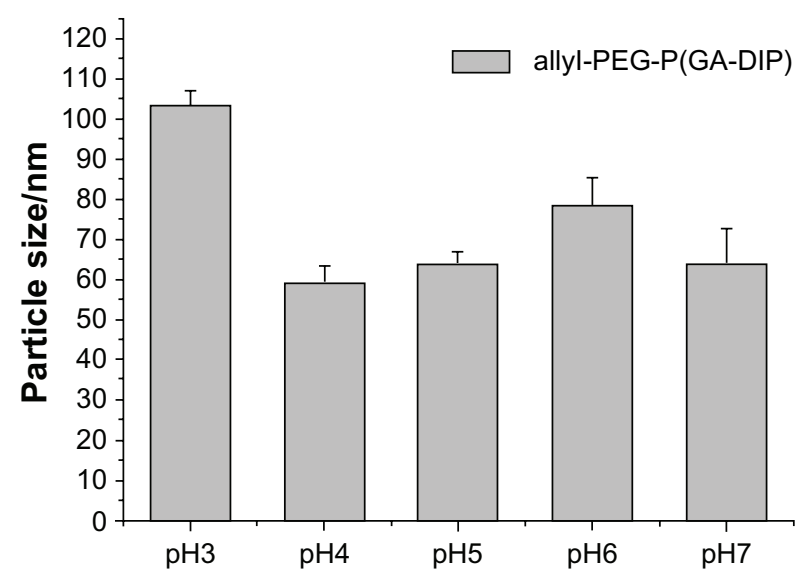

Figure 5 Particle sizes of DOX and SPION-loaded allyl-PEG-P(GA-DIP) micelles at $\mathrm{pH} 3.0-7.0$.

Abbreviations: allyl-PEG-P(GA-DIP), allyl-poly(ethylene glycol)-b-poly[N-(N', $N^{\prime}$ diisopropylaminoethyl) glutamine]; DOX, doxorubicin; SPIONs, superparamagnetic iron oxide nanoparticles.

As we can see, all of the micelles' particle sizes also slightly decreased from 64.2 to $59.9 \mathrm{~nm}$ except the one at $\mathrm{pH} 6.0$, while the $\mathrm{pH}$ value of the micelle solution decreased from 7.0 to 4.0. In this process, the charge property of some acid-responsive groups would vary with the concentration of hydrogen protons $\left(\mathrm{H}^{+}\right)$. For example, DIP groups would be protonated to be more and more hydrophilic, and electropositive, with the decrease of $\mathrm{pH}$ values (from $\mathrm{pH} 10.0$ to 5.5$).^{41,42}$ This was a process of dynamic balance, especially in view of the existence of PGA's side carboxyl groups with the opposite charge. At $\mathrm{pH}$ 6.0, DIP groups could not be fully protonized, which was not enough to neutralize the residual negative side carboxyl groups of PGA $\left(\mathrm{pK}_{\mathrm{a}} \approx 4.25\right)$. The amount of positive and negative charges could not keep equilibrium at $\mathrm{pH}$ 6.0, but could do so at $\mathrm{pH} 4.0$. So these acid-sensitive micelles were enlarged at $\mathrm{pH} 6.0$ and were smallest at $\mathrm{pH}$ 4.0.

Importantly, all micelles generating positive charges of DIP would also form the strong electric attraction with the PGA's residual negative carboxyl groups (from $\mathrm{pH} 6.0$ to 4.0), which built up the core cross-linking structure and micellar stability. In this process, the acid-sensitivity of DIP could be continuously electropositive. The electric attraction could strengthen between the electropositive DIP groups and the remaining electronegative carboxyl groups of PGA ( $\mathrm{pK}_{\mathrm{a}} \approx 4.25$ ), because $50 \%$ of the carboxyl groups of PGA were not grafted with the DIP.

The particle size of the nanomicelles had an outstanding enlargement at a $\mathrm{pH}$ of 3.0. As this $\mathrm{pH}$ value was significantly lower than the PGA's $\mathrm{pK}_{\mathrm{a}}(\approx 4.25)$, all of the remaining carboxyl groups of PGA would be completely electroneutral according to the carboxyl groups' individual properties. In this case, the electric attraction and cross-linking between the $\mathrm{P}(\mathrm{GA}-\mathrm{DIP})$ groups and the remaining carboxyl groups would disappear. In contrast, the mutual repulsion had an obvious effect inside the protonated electropositive DIP groups at a $\mathrm{pH}$ of 3.0. Hence, the micelles quickly expanded to $103.1 \mathrm{~nm}$.

Figure 3 describes the size and change in cross-linking of acid-triggered nanomicelles at different $\mathrm{pH}$ environments.

\section{Drug release from various drug-loaded nanomicelles} The release of DOX from various DOX-loaded nanomicelles was studied at a pH of 5.0 or 7.0 (Figure 6). At a pH of 7.0, less than $20 \%$ of the DOX in all of the nanomicelles was released after 30 days. All of the nanomicelles demonstrated slow DOX release in the neutral environment.

However, at a pH of 5.0, DOX release in the allyl-PEG$\mathrm{P}(\mathrm{GA}-\mathrm{DIP})$ micelles was greatly accelerated. After 2 days, $41.5 \%$ of the DOX was released from the allyl-PEG-P(GADIP) micelles. Only $11.4 \%$ and $10.3 \%$ of the DOX in PEGPDLLA and PEG-PCL micelles were released, respectively. After 27 days, half of the DOX was released from the allylPEG-P(GA-DIP) micelles at a $\mathrm{pH}$ of 5.0 , and $40.2 \%$ and $15.5 \%$ of the DOX in PEG-PDLLA and PEG-PCL micelles were ultimately released, respectively.

For PEG-PDLLA, its good degradability and short hydrophobic blocks (only $2000 \mathrm{~g} / \mathrm{mol}$ ) facilitated rapid micelle disassembly, catalyzed by high acid concentrations. For allyl-PEG-P(GA-DIP), a pH of 5.0 was much lower than the DIP's $\mathrm{pK}_{\mathrm{a}}(\approx 6.3)$, so that the $\mathrm{P}(\mathrm{GA}-\mathrm{DIP})$ groups could be electropositive and hydrophilic. At a $\mathrm{pH}$ of 5.0, it was close to the $\mathrm{pK}_{\mathrm{a}}$ of the PGA's remaining carboxyl groups $\left(\mathrm{pK}_{\mathrm{a}} \approx 4.25\right)$, and the partially remaining carboxyl groups became weakly electronegative or even electroneutral according to their individual properties. Under these conditions, the cross-linking between the electropositive P(GA-DIP) groups and the remaining carboxyl groups (electronegative or even electroneutral) decreased. Moreover, the hydrophobic P(GA-DIP) blocks changed into the hydrophilic ones. Due to the decreased cross-linking and the increased hydrophilic P(GA-DIP), the encapsulated DOX could be released quickly. This hydrophilic transformation of the $\mathrm{P}$ (GA-DIP) core occurred earlier than the visible change in its size. It is possible that DOX could be also released quickly in endosomes and lysosomes, where the $\mathrm{pH}$ environment was close to or slightly lower than 5.0.

Specific and fast drug release from acid-triggered nanomicelles was very effective inside the cancer cells. In some 


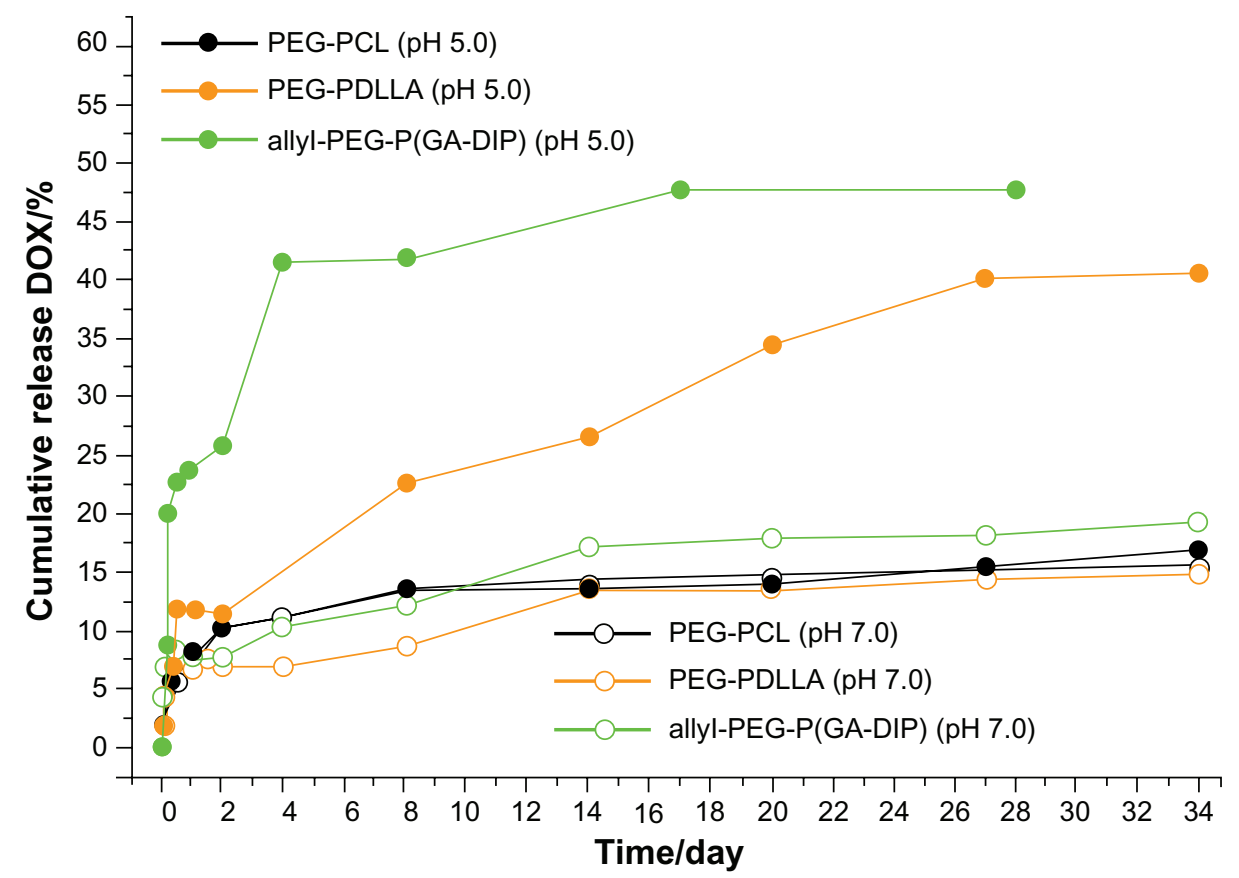

Figure 6 Drug release from various nanomicelles at different $\mathrm{pH}$.

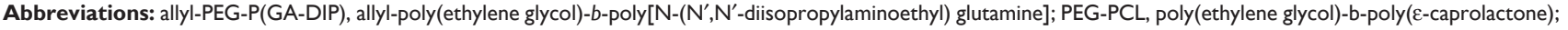
PEG-PDLLA, poly(ethylene glycol)-b-poly(D,L-lactic acid).

previous reports, the $\mathrm{pH}$-catalyzed hydrolysis of drug-polymer linkages in the polymer drugs had rapid drug release rates and high drug efficacy. ${ }^{43,44}$ The lysosomal membrane could hinder the location of the ingested nanomicelles. The encapsulated drugs in the nanomicelles were mainly released in the lysosome. Hence, the small size of the released drugs easily permeated the lysosomal membrane to reach the targeted site.

\section{Cell biology experiment}

Fluorescence microscopy

In the cell-uptake test of nanomicelles (Figure 7, 100×), the red-colored DOX fluorescence could be seen in the micelle groups (DOX concentration: 0.19 and $0.76 \mu \mathrm{g} / \mathrm{mL}$ ), indicating the successful DOX encapsulation in the cells. The fluorescence intensity became strong, while the DOX concentration increased. This also confirmed that DOX encapsulated in micelles entered the cancer cell.

In the targeted test (Figure 8, 100×), the red-colored DOX fluorescence of the targeted group was obvious. The relative fluorescence intensity of the folate-targeted group (86.8\%) was higher than that of other groups (Figure 9). In the competitive inhibition and the non-targeted groups, a weak DOX fluorescence was observed. The weak relative fluorescence intensity of the non-targeted group was $56.1 \%$, which was lower than that of the targeted group. Particularly, the free folic acid in the competitive inhibition group was also associated with a folic-receptor, which inhibited further
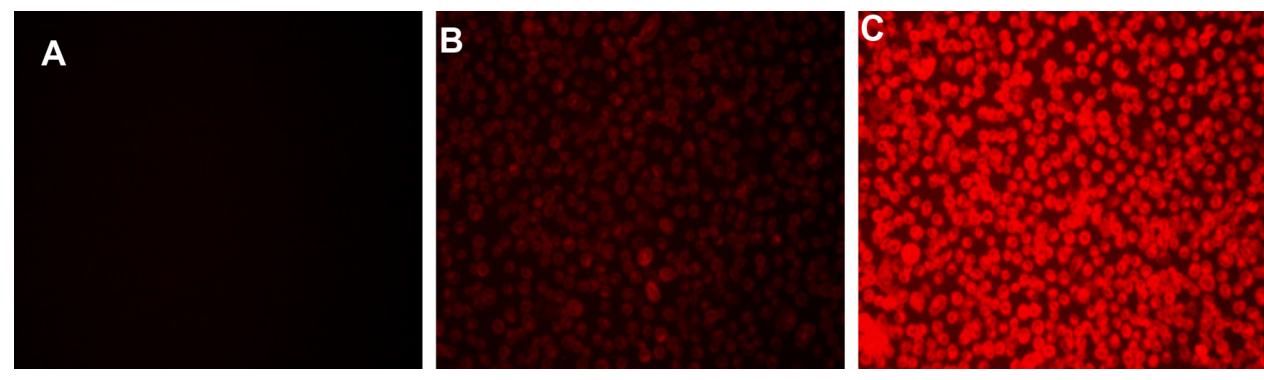

Figure 7 Fluorescence microscope images.

Notes: Bel-7402 cells incubated with PBS and folate-PEG-P(GA-DIP) at different DOX concentrations ( $\mu \mathrm{g} / \mathrm{mL})$ for 2 hours. (A) PBS control; (B) $0.19 \mu \mathrm{g} / \mathrm{mL}$; (C) $0.76 \mu \mathrm{g} / \mathrm{mL}$. Abbreviations: DOX, doxorubicin; folate-PEG-P(GA-DIP), folate-poly(ethylene glycol)-b-poly[ $\mathrm{N}^{-}\left(\mathrm{N}^{\prime}, \mathrm{N}^{\prime}\right.$-diisopropylaminoethyl) glutamine]; PBS, phosphate-buffered saline. 

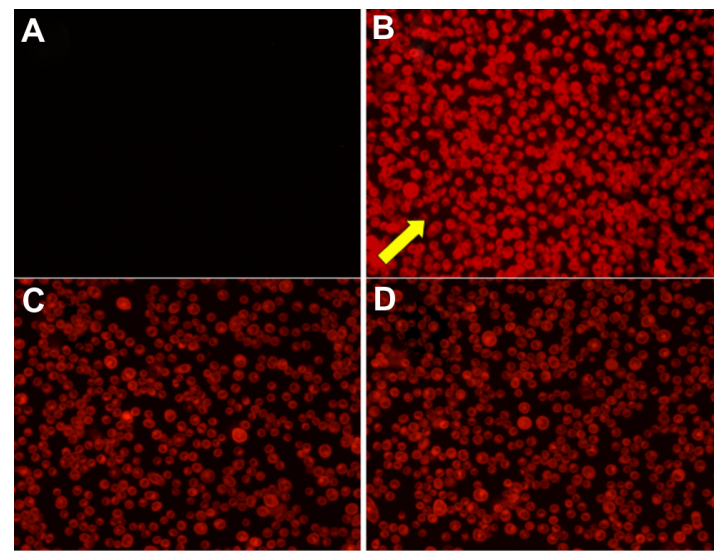

Figure 8 Fluorescence microscope images.

Notes: Bel-7402 cells were incubated with different samples. (B-D) set to the same $0.76 \mu \mathrm{g} / \mathrm{mL}$ DOX concentration. Arrow: clear DOX fluorescence in targeted group. (A) PBS control; (B) Targeted group: folate-PEG-P(GA-DIP); (C) Non-targeted group: PEG-P(GA-DIP); (D) The competitive inhibition group: folate-PEG-P(GADIP) and I $\mathrm{mM}$ free folic acid.

Abbreviations: DOX, doxorubicin; folate-PEG-P(GA-DIP), folate-poly(ethylene glycol)$b$-poly[N-(N',N'-diisopropylaminoethyl) glutamine]; PBS, phosphate-buffered saline.

connections between targeted micelles and receptors to generate the low relative fluorescence intensity (45.5\%). The folate-targeted effect enhanced the cell uptake of folatePEG-P(GA-DIP) nanomicelles loading DOX, showing that the linkage between folic acid and the acid-responsive PEG$\mathrm{P}$ (GA-DIP) copolymer worked well in liver cancer cells.

\section{In vitro $M R I$ scans}

Compared to the PBS control without cells, the cells suspended in the gelatin control group had a lower signal. The gelatin

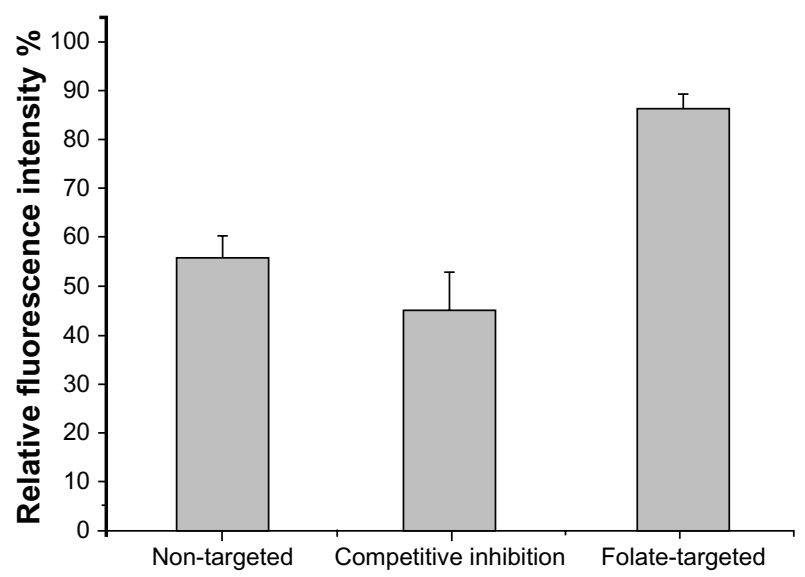

Figure 9 Relative fluorescence intensity by comparing fluorescence of different test groups to that of free DOX contrast group.

Notes: Bel-7402 cells were incubated with different test samples. In the contrast group, the free DOX solution was incubated with cells. DOX concentration was $0.76 \mu \mathrm{g} / \mathrm{mL}$ in all groups. Non-targeted: cells mixed with folate-PEG-P(GA-DIP). Competitive inhibition: cells mixed with folate-PEG-P(GA-DIP) and I mM free folic acid. Folate-targeted: cells mixed with folate-PEG-P(GA-DIP).

Abbreviations: DOX, doxorubicin; folate-PEG-P(GA-DIP), folate-poly(ethylene glycol)-b-poly[N-( $\mathrm{N}^{\prime}, \mathrm{N}^{\prime}$-diisopropylaminoethyl) glutamine $]$.

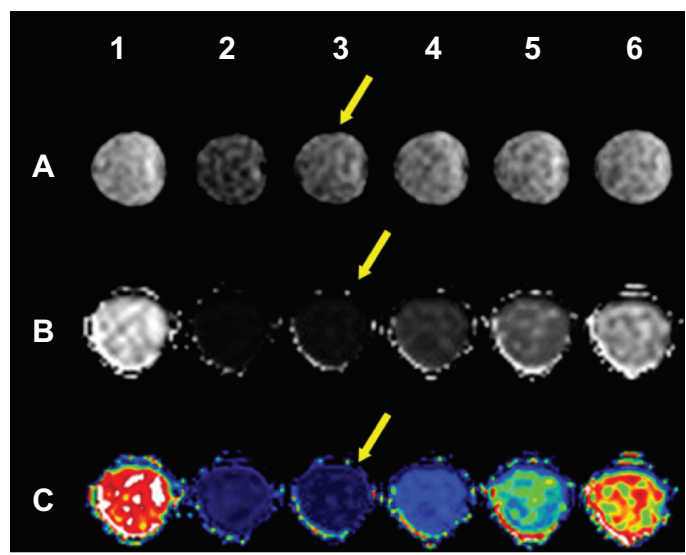

Figure 10 (A) T2-weighted, (B) T2-mapping, and (C) colored T2-mapping images. Notes: The $2-5$ test groups were incubated with folate-PEG-P(GA-DIP) at different Fe concentrations for 2 hours. Then cells in the $2-5$ groups were suspended in gelatin. (1) PBS contrast without cells; (2) $0.358 \mu \mathrm{g} / \mathrm{mL}$; (3) $0.179 \mu \mathrm{g} / \mathrm{mL}$; (4) 0.0895 $\mu \mathrm{g} / \mathrm{mL}$; (5) $0.04475 \mu \mathrm{g} / \mathrm{mL}$; (6) Gelatin contrast with cells, which were not incubated with micelles. Arrow: clear decreased signal.

Abbreviations: folate-PEG-P(GA-DIP), folate-poly(ethylene glycol)-b-poly[N$\left(\mathrm{N}^{\prime}, \mathrm{N}^{\prime}\right.$-diisopropylaminoethyl) glutamine]; PBS, phosphate-buffered saline.

was used to keep the cell suspension stable. In the uptake test (Figure 10), the T2 signal intensity decreased, while the Fe concentration increased. SPIONs were successfully encapsulated into the folate-PEG-P(GA-DIP) nanomicelles. Hence, nanomicelles loading SPIONs were indeed transported into the cells. The drug concentration in the nanomicelles impacted the signal intensity. A low signal was clearly observed for the $0.179 \mu \mathrm{g} / \mathrm{mL}$ Fe concentration group. Hence, this Fe concentration group was chosen for the next target test. In Figure 11, T2 values of several different groups were calculated.

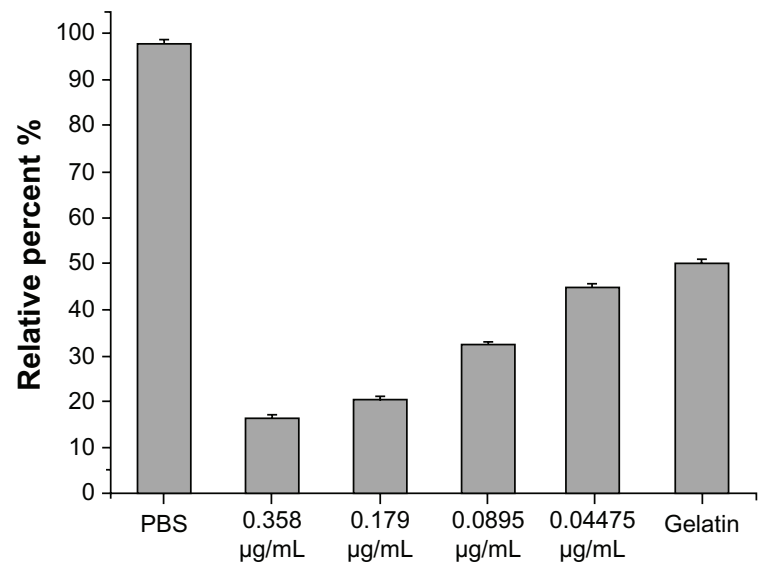

Figure I I Signal relative percent obtained by comparing T2 values at different test groups to the pure water.

Notes: The $2-5$ test groups were incubated with folate-PEG-P(GA-DIP) at different Fe concentrations for 2 hours. Then cells in the $2-5$ groups were suspended in gelatin. (1) PBS contrast without cells; (2) $0.358 \mu \mathrm{g} / \mathrm{mL}$; (3) $0.179 \mu \mathrm{g} / \mathrm{mL}$; (4) 0.0895 $\mu \mathrm{g} / \mathrm{mL}$; (5) $0.04475 \mu \mathrm{g} / \mathrm{mL}$; (6) Gelatin contrast with cells, which were not incubated with micelles.

Abbreviations: folate-PEG-P(GA-DIP), folate-poly(ethylene glycol)-b-poly[N( $\mathrm{N}^{\prime}, \mathrm{N}^{\prime}$-diisopropylaminoethyl) glutamine]; PBS, phosphate-buffered saline. 


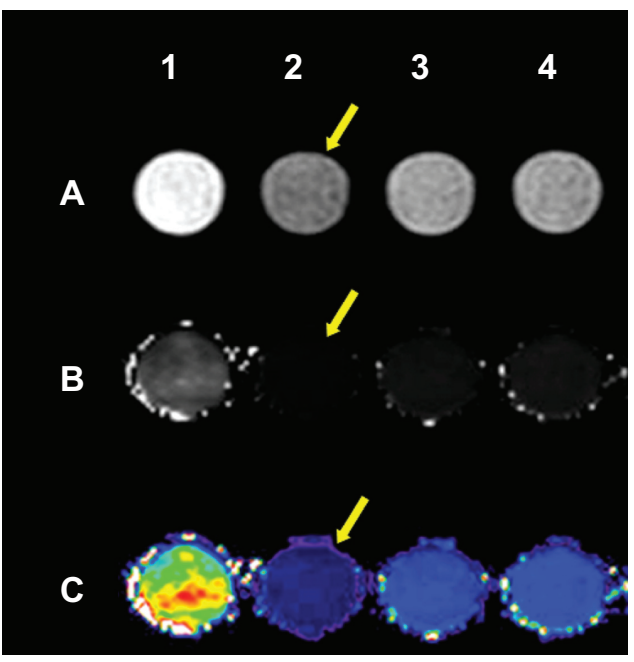

Figure 12 (A) T2-weighted, (B) T2-mapping, and (C) colored T2-mapping images. Notes: Test groups were incubated with different samples for 2 hours. The 2-4 groups set to $0.179 \mu \mathrm{g} / \mathrm{mL}$ Fe concentration. (I) Gelatin contrast with cells, which were not incubated with micelles; (2) Targeted group: folate-PEG-P(GA-DIP); (3) Non-targeted group: PEG-P(GA-DIP); (4) Competitive inhibition group: folatePEG-P(GA-DIP) micelles with I mM free folic acid. Arrow: clear decreased signal in targeted group.

Abbreviation: folate-PEG-P(GA-DIP), folate-poly(ethylene glycol)-b-poly[N( $N^{\prime}, N^{\prime}$-diisopropylaminoethyl) glutamine]

In the targeted test, the signal of the folate-targeted group was lower than that of the non-targeted group and the competitive inhibition group (Figures 12 and 13). The targeted effect was attributed to the high affinity of folate-receptor mediated endocytosis. ${ }^{45,46}$ The PEG-P(GA-DIP) nanomicelles did not have the folate-ligands. Some PEG-P(GA-DIP) nanomicelles

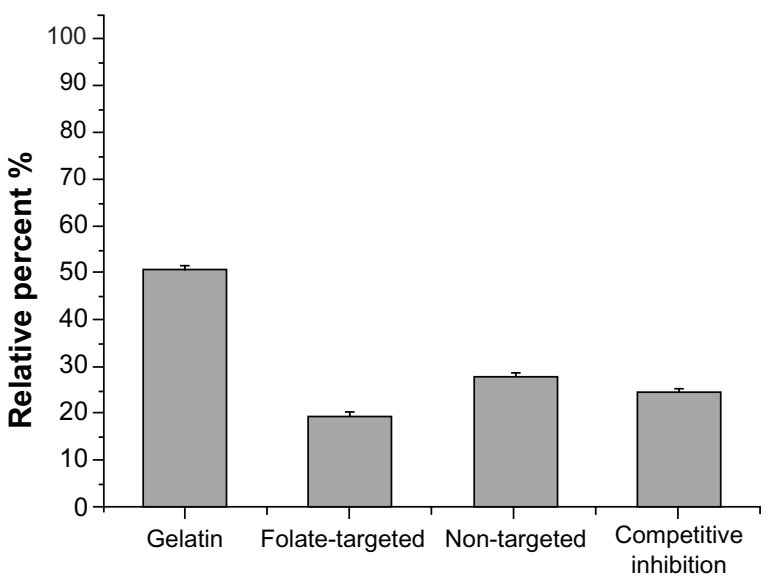

Figure 13 Signal relative percent obtained by comparing T2 values at different test groups to the pure water.

Notes: Test groups were incubated with different samples for 2 hours. The 2-4 groups set to $0.179 \mu \mathrm{g} / \mathrm{mL}$ Fe concentration. (I) Gelatin contrast with cells, which were not incubated with micelles; (2) Targeted group: folate-PEG-P(GA-DIP); (3) Non-targeted group: PEG-P(GA-DIP); (4) Competitive inhibition group: folatePEG-P(GA-DIP) micelles with I mM free folic acid.

Abbreviation: folate-PEG-P(GA-DIP), folate-poly(ethyleneglycol)-b-poly[N-(N',N'diisopropylaminoethyl) glutamine]. were transported into the cells by cell endocytosis. In the competitive inhibition group, the free folic acid decreased the linkage between the folate-targeted nanomicelles and the folate receptors of the cells.

The folate-targeted effect existed in both the primary tumors and metastases. A previous study indicated that folate receptors could be expressed significantly in the squamous cell carcinoma of the head and neck, both in primary tumors and in the corresponding lymph node metastases. ${ }^{47}$ The high expression of folate receptors appeared to be correlated with the clinical outcomes. Folate receptors in metastatic lymph nodes suggested a strong potential for targeted chemotherapy in both primary tumor and metastasis. If a tiny metastasis cannot be detected by normal imaging methods, this targeted effect in metastasis could be considered. The folate-targeted nanomicelles could be used to treat the tiny metastasis and prevent tumor recurrence.

\section{Conclusion}

On the basis of the grafted DIP groups, the PEG-P(GA-DIP) block copolymer demonstrated good acid responsiveness and improved cellular uptake of encapsulated DOX and SPIONs for effective cancer therapy and diagnosis. Moreover, the linkage of folic acid with PEG-P(GA-DIP) further facilitated drug delivery by nanomicelles to targeted cancer cells.

\section{Acknowledgments}

This work was supported by the National Natural Science Foundation of China (Grant No 30973419) and the Science and Technology Project of Guangdong Province (No 2010B060900048).

\section{Disclosure}

The authors report no conflicts of interest in this work.

\section{References}

1. Hong G, Yuan R, Liang B, Shen J, Yang X, Shuai X. Folatefunctionalized polymeric micelle as hepatic carcinoma-targeted, MRIultrasensitive delivery system of antitumor drugs. Biomed Microdevices. 2008;10(5):693-700.

2. Corot C, Robert P, Idée M, Port M. Recent advances in iron oxide nanocrystal technology for medical imaging. Adv Drug Deliv Rev. 2006; 58(14):1471-1504.

3. Mahmoudi M, Sant S, Wang B, Laurent S, Sen T. Superparamagnetic iron oxide nanoparticles (SPIONs): Development, surface modification and applications in chemotherapy. Adv Drug Deliv Rev. 2011;63(1-2):24-46.

4. Yang X, Grailer JJ, Rowland IJ, et al. Multifunctional SPIO/DOXloaded wormlike polymer vesicles for cancer therapy and MR imaging. Biomaterials. 2010;31(34):9065-9073.

5. Yoon HY, Saravanakumar G, Heo R, et al. Hydrotropic magnetic micelles for combined magnetic resonance imaging and cancer therapy. $J$ Control Release. 2012;160(3):692-698. 
6. Wang C, Ravi S, Martinez GV, et al. Dual-purpose magnetic micelles for MRI and gene delivery. J Control Release. 2012;163(1):82-92.

7. Liu TY, Wu MY, Lin MH, Yang FY. A novel ultrasound-triggered drug vehicle with multimodal imaging functionality. Acta Biomater. 2013;9(3): 5453-5463.

8. Talelli M, Iman M, Varkouhi AK, et al. Core-crosslinked polymeric micelles with controlled release of covalently entrapped doxorubicin. Biomaterials. 2010;31(30):7797-7804.

9. Talelli M, Iman M, Rijcken CJ, van Nostrum CF, Hennink WE. Targeted core-crosslinked polymeric micelles with controlled release of covalently entrapped doxorubicin. J Control Release. 2010;148(1):e121-e122.

10. Crielaard BJ, Rijcken CJ, Quan L, et al. Glucocorticoid-Loaded corecross-linked polymeric micelles with tailorable release kinetics for targeted therapy of rheumatoid arthritis. Angew Chem Int Ed Engl. 2012;51(29):7254-7258.

11. Chan Y, Wong T, Byrne F, Kavallaris M, Bulmus V. Acid-labile core cross-linked micelles for $\mathrm{pH}$-triggered release of antitumor drugs. Biomacromolecules. 2008;9(7):1826-1836.

12. Talelli M, Rijcken CJ, Oliveira S, et al. Reprint of "Nanobody-shell" functionalized thermosensitive core-crosslinked polymeric micelles for active drug targeting. J Control Release. 2011;153(1):93-102.

13. Abdullah-Al-Nahain, Lee H, Lee YS, Lee KD, Park SY. Development of disulfide core-crosslinked pluronic nanoparticles as an effective anticancer-drug-delivery system. Macromol Biosci. 2011;11(9):1264-1271.

14. Zhang Z, Yin L, Tu C, et al. Redox-Responsive, Core Cross-Linked Polyester Micelles. ACS Macro Lett. 2013;2(1):40-44.

15. Yan L, Wu W, Zhao W, et al. Reduction-sensitive core-cross-linked mPEG-poly(ester-carbonate) micelles for glutathione-triggered intracellular drug release. Polym Chem. 2012;3(9):2403-2412.

16. Bronich TK, Keifer PA, Shlyakhtenko LS, Kabanov AV. Polymer micelle with cross-linked ionic core. J Am Chem Soc. 2005;127(23): 8236-8237.

17. Kakizawa Y, Harada A, Kataoka K. Environment-sensitive stabilization of core-shell structured polyion complex micelle by reversible cross-linking of the core through disulfide bond. J Am Chem Soc. 1999;121(48):11247-11248.

18. Barreiro-Iglesias R, Bromberg L, Temchenko M, Hatton TA, AlvarezLorenzo C, Concheiro A. Pluronic-g-poly(acrylic acid) copolymers as novel excipients for site specific, sustained release tablets. Eur J Pharm Sci. 2005;26(5):374-385.

19. Wang $\mathrm{X}, \mathrm{Wu} \mathrm{G}, \mathrm{He} \mathrm{T}$, et al. Novel $\mathrm{pH}$-sensitive zwitterionic poly (amino acid) derivatives for drug delivery. J Control Release. 2011;152 (Suppl 1):e93-e94.

20. Chécot F, Rodríguez-Hernández J, Gnanou Y, Lecommandoux S. $\mathrm{pH}$-responsive micelles and vesicles nanocapsules based on polypeptide diblock copolymers. Biomol Eng. 2007;24(1):81-85.

21. Chen Y, Dong CM. pH-Sensitive supramolecular polypeptide-based micelles and reverse micelles mediated by hydrogen-bonding interactions or host-guest chemistry: characterization and in vitro controlled drug release. J Phys Chem B. 2010;114(22):7461-7468.

22. Bae Y, Nishiyama N, Kataoka K. In vivo antitumor activity of the folate-conjugated $\mathrm{pH}$-sensitive polymeric micelle selectively releasing adriamycin in the intracellular acidic compartments. Bioconjug Chem. 2007;18(4):1131-1139

23. Oh KT, Kim D, You HH, Ahn YS, Lee ES. pH-sensitive properties of surface charge-switched multifunctional polymeric micelle. Int JPharm. 2009;376(1-2):134-140.

24. Ito Y, Ochiai Y, Park YS, Imanishi Y. pH-sensitive gating by conformational change of a polypeptide brush grafted onto a porous polymer membrane. J Am Chem Soc. 1997;119(7):1619-1623.

25. Gil ES, Hudson SM. Stimuli-responsive polymers and their bioconjugates. Prog Polym Sci. 2004;29(12):1173-1222.

26. Bories-Azeau X, Armes SP, Van den Haak HJW. Facile synthesis of zwitterionic diblock copolymers without protecting group chemistry. Macromolecules. 2004;37(7):2348-2352.

27. Parker N, Turk MJ, Westrick E, Lewis JD, Low PS, Leamon CP. Folate receptor expression in carcinomas and normal tissues determined by a quantitative radioligand binding assay. Anal Biochem. 2005;338(2):284-293.
28. Cammas S, Nagasaki Y, Kataoka K. Heterobifunctional poly(ethylene oxide): synthesis of alpha-methoxy-omega-amino and alpha-hydroxyomega-amino PEOs with the same molecular weights. Bioconjug Chem. 1995;6(2):226-230.

29. Yang XQ, Deng WJ, Fu LW, et al. Folate-functionalized polymeric micelles for tumor targeted delivery of a potent multidrug-resistance modulator FG020326. J Biomed Mater Res A. 2008;86(1): 48-60.

30. Wang Y, Goethals EJ, Du Prez FE. Association behavior between endfunctionalized block copolymers PEO-PPO-PEO and poly(acrylic acid). Macromol Chem Phys. 2004;205(13):1774-1781.

31. Wang L, Wang S, Bei J. Synthesis and characterization of macroinitiator-amino terminated PEG and poly( $\gamma$-benzyl-L-glutamate)-PEOpoly( $\gamma$-benzyl-L-glutamate) triblock copolymer. Polym Adv Technol. 2004;15(10):617-621.

32. Blout ER, Karlson RH. Polypeptides. III. The synthesis of high molecular weight poly-r-benzyl-L-glutamates ${ }^{1} . J$ Am Chem Soc. 1956;78(5):941-946.

33. Goodman M, Hutchison J. The mechanisms of polymerization of N-unsubstituted N-carboxyanhydride ${ }^{1}$. J Am Chem Soc. 1966; 88(15):3627-3630.

34. Poché DS, Moore MJ, Bowles JL. An unconventional method for purifying the $\mathrm{N}$-carboxyanhydride derivatives of $\gamma$-alkyl-L-glutamates. Synthetic Comm. 1999;29(5):843-854.

35. Barbosa MEM, Montembault V, Cammas-Marion S, Ponchel G, Fontaine L. Synthesis and characterization of novel poly $(\gamma$-benzyl-Lglutamate) derivatives tailored for the preparation of nanoparticles of pharmaceutical interest. Polym Int. 2007;56(3):317-324.

36. Ding W, Lin S, Lin J, Zhang L. Effect of chain conformational change on micelle structures: experimental studies and molecular dynamics simulations. J Phys Chem B. 2008;112(3):776-783.

37. Pan SR, Wang QM, Yi W. Study on aminolysis of poly benzyl glutamate and its biodegradability. J Functional Materials. 2000;31(2): 215-218.

38. Zhang G, Zhang R, Wen XX, Li L, Li C. Micelles based on biodegradable poly(L-glutamic acid)-b-polylactide with paramagnetic Gd ions chelated to the shell layer as a potential nanoscale MRI-visible delivery system. Biomacromolecules. 2008;9(1):36-42.

39. Diao YY, Li HY, Fu YH, et al. Doxorubicin-loaded PEG-PCL copolymer micelles enhance cytotoxicity and intracellular accumulation of doxorubicin in adriamycin-resistant tumor cells. Int $J$ Nanomedicine. 2011;6:1955-1962.

40. Sun S, Zeng H, Robinson DB, et al. Monodisperse $\mathrm{MFe}_{2} \mathrm{O}_{4}(\mathrm{M}=\mathrm{Fe}$, Co, Mn) nanoparticles. J Am Chem Soc. 2004;126(1):273-279.

41. Du J, Tang Y, Lewis AL, Armes SP. pH-Sensitive vesicles based on a biocompatible zwitterionic diblock copolymer. J Am Chem Soc. 2005;127(51):17982-17983.

42. Nakanishi M, Park JS, Jang WD, Oba M, Kataoka K. Study of the quantitative aminolysis reaction of poly(b-benzyl L-aspartate) (PBLA) as a platform polymer for functionality materials. React Funct Polym. 2007;67(11):1361-1372.

43. Gillies ER, Fréchet JMJ. pH-responsive copolymer assemblies for controlled release of doxorubicin. Bioconjug Chem. 2005;16(2):361-368.

44. Kamada H, Tsutsumi Y, Yoshioka Y, et al. Design of a pH-sensitive polymeric carrier for drug release and its application in cancer therapy. Clin Cancer Res. 2004;10(7):2545-2550.

45. Wang F, Chen Y, Zhang D, et al. Folate-mediated targeted and intracellular delivery of paclitaxel using a novel deoxycholic acid-O-carboxymethylated chitosan-folic acid micelles. Int J Nanomedicine. 2012;7:325-337.

46. Yang H, Lou C, Xu M, Wu C, Miyoshi H, Liu Y. Investigation of folateconjugated fluorescent silica nanoparticles for targeting delivery to folate receptor-positive tumors and their internalization mechanism. Int J Nanomedicine. 2011;6:2023-2032.

47. Saba NF, Wang X, Müller S, et al. Examining expression of folate receptor in squamous cell carcinoma of the head and neck as a target for a novel nanotherapeutic drug. Head Neck. 2009;31(4): 475-481. 
International Journal of Nanomedicine

Dovepress

\section{Publish your work in this journal}

The International Journal of Nanomedicine is an international, peerreviewed journal focusing on the application of nanotechnology in diagnostics, therapeutics, and drug delivery systems throughou the biomedical field. This journal is indexed on PubMed Central, MedLine, CAS, SciSearch ${ }^{\circledR}$, Current Contents ${ }^{\circledR} /$ Clinical Medicine,
Journal Citation Reports/Science Edition, EMBase, Scopus and the Elsevier Bibliographic databases. The manuscript management system is completely online and includes a very quick and fair peer-review system, which is all easy to use. Visit http://www.dovepress.com/ testimonials.php to read real quotes from published authors.

Submit your manuscript here: http://www.dovepress.com/international-journal-of-nanomedicine-journal 